Journal of Biotechnology and Strategic Health Research

\author{
Research Article / Araştırma Makalesi
}

http://dergipark.org.tr/tr/pub/bshr

\title{
Aktif Ortodontik Tedavi Gören Hastalarda COVID-19 Salgını Süresinde Braketin Dişten Ayrılması ve Oral Hijyen Durumu
}

\author{
Bracket Failure from the Tooth and Oral Hygiene Status During the COVID-19 \\ Outbreak in Patients Receiving Active Orthodontic Treatment
}

\section{Refika Topal}

Sakarya Üniversitesi Diş Hekimliği Fakültesi Ortodonti Anabilim Dalı, Sakarya, Türkiye

ORCID ID: Refika Topal, https://orcid.org/0000-0002-1961-127X

*Sorumlu Yazar / Corresponding Author: Dr. Öğr. Üyesi Refika Topal, e-posta / e-mail: refikatopal@hotmail.com

Geliş Tarihi / Received: 17-09-2020 Kabul Tarihi / Accepted: 19-09-2020 Yayın Tarihi / Online Published: 31-12-2020

Atıf Gösterimi/How to Cite: Topal R. Aktif Ortodontik Tedavi Gören Hastalarda COVID-19 Salgını Süresinde Braketin Dişten Ayrılması ve Oral Hijyen Durumu, J Biotechnol and Strategic Health Res. 2020;4(3):266-271

\begin{tabular}{|c|c|}
\hline \multicolumn{2}{|l|}{ Özet } \\
\hline Amaç & $\begin{array}{l}\text { Bu araştırmada COVID-19 salgını süresinde aktif ortodontik tedavisi devam etmekte olan hastalarda dișten ayrılan braket sayılarını ve oral hijyen durumlarını tespit } \\
\text { etmek amaçlanmıștır. }\end{array}$ \\
\hline Yöntem & $\begin{array}{l}\text { Çalışmaya ortodonti kliniğinde tedavisi devam etmekte olan } 102 \text { hasta davet edilmiş ve bütün hastalar çalışmaya katılmayı kabul etmiştir. Araștırmada değişkenler } \\
\text { hastaların cinsiyet ve yaşa göre plak indeks (PI) değerleri ve kırılan braket sayıları değerlendirilmiştir. Analizlerde bağımsız örneklemler için t testi, one-way ANOVA } \\
\text { ve Ki-kare testi kullanılmıștır. }\end{array}$ \\
\hline Bulgular & $\begin{array}{l}\text { Hastalarımızda erkeklerin kadınlara göre plak indeks (PI) değerlerinin daha yüksek olduğu görülmüștür }(\mathrm{p}<0,05) \text {. Kadın hastalarımızın da erkek hastalarımıza göre } \\
\text { daha fazla braket kırdığı görülmüştür }(\mathrm{p}<0,05) \text {. }\end{array}$ \\
\hline Sonuç & COVID-19 pandemisinin bașlangıç süresinde aktif ortodontik tedavisi devam eden hastalarımızda oral hijyeni sağlamakta yetersiz kaldıkları görülmüștür. \\
\hline $\begin{array}{r}\text { Anahtar } \\
\text { kelimeler }\end{array}$ & COVID-19, Pandemi, Ortodontik Tedavi \\
\hline \multicolumn{2}{|l|}{ Abstract } \\
\hline Aim & The aim of this study is to determine the number of failure brackets and oral hygienic status in patients on going active orthodontic treatment during the COVID-19 outbreak process. \\
\hline Methods & $\begin{array}{l}\text { For this study, } 102 \text { patients actively receiving treatment in the department of orthodontics were invited and all the patients accepted the participation. The parameters in the present study } \\
\text { were examined using plaque index (PI) and number of broken brackets depending on the age and gender of participants. Independent samples t-test, One-Way ANOVA, and Chi-square } \\
\text { test were used in the analyses. }\end{array}$ \\
\hline Results & It was determined that men had higher level of plaque index (PI) values than women $(p<0,05)$. It was also observed that female break more brackets than male $(p<0,05)$. \\
\hline
\end{tabular}




\section{GIIRIŞ}

2019 aralık ayında Çin'in Wuhan şehrinde bilim insanları tarafından atipik bir pnömoni türü tespit edilmiştir. 2020 ocak ayında Çinli bilim insanları hastalığa neden olan patojeni COVID-19 olarak tanımlamıştır. Hastalıkta yayılım ve bulaş hızı çok yüksek olup sadece Çin etkilenmekle kalmayıp kısa sürede dünyadaki bütün ülkelerde eş zamanlı yayılım göstermiştir. 30 Ocak 2020'de Dünya Sağlık Örgütü (WHO) bu salgını uluslararası ve endişe verici bir halk sağlığı sorunu olduğunu açıklamıştır. ${ }^{1} 11$ Mart 2020 tarihi itibari ile DSÖ tarafından pandemi olarak ilan edilmiştir. Türkiye'de ilk COVID-19 vakası 10 Mart 2020'de ve ilk COVID-19 kaynaklı ölüm 17 Mart 2020 tarihinde görülmüştür. ${ }^{2}$ Ortaya çıkan tablo ile Türkiye'de salgının yayılmasını önlemeye yönelik bazı tedbirlerin alınması gerekliliğini ortaya çıkarmış ve bu anlamda ilk vakanın tespiti ile birlikte önlemler alınmıştır. Bu kapsamda eğitim öğretime ara verilmiş, seyahat kısıtlamaları getirilmiş, yurt dışından gelenlerde 14 gün karantina uygulaması, belirli yaş gruplarına sokağa çıkma yasağı getirilmiş, sosyal izolasyon uygulanması vurgulanmış, belirli günlerde bütün bireyleri kapsayan sokağa çıkma yasağı uygulanmış, ortak kullanım alanları kapatılmış, gerekli acil durumlar dışında diş tedavilerinde erteleme kararı alınmıştır. Aniden yapılmış olan bu kisitlamalar bireylerde istenmeyen ruhsal sıkıntıların ortaya çıkmasına sebep olmuştur. Bireylerde sadece COVID-19 kaynaklı viral enfeksiyondan kaynaklı ölüm riski değil aynı zamanda sosyal izalasyonla birlikte, yüksek düzeyde psikolojik baskı meydana geldiği belirtilmiştir. ${ }^{3}$ COVID-19 enfeksiyonundan korunmak için 17.03.2020 tarihinde diş hekimliği uygulamaları ve dental kliniklerde alınabilecek önlemler kapsamında T.C. Sağlık Bakanlığı Sağlık Hizmetleri Genel Müdürlüğünce elektif işlemleri ertelemesini ve acil olmayan diş hekimliği uygulamalarını mümkün olduğunca ertelenmesi önerilmiştir. 23.03.2020 tarihli Bilim Kurulu kararlarına göre; ortodontik tedaviler için, ortodontik tedavi gören hastaların braket ve tellerinin yerinden çıkması veya kırılması şeklinde tanımlanmıştır. ${ }^{4}$

Sabit ortodontik tedavilerde başarılı olmak ve etkin bir te- davi gerçekleştirebilmek için braketlerin diş yüzeyine yeterli tutuculukta yapıştırılabilmesi gerekmektedir. ${ }^{5}$ Başarılı bir bonding işlemi için adeziv sistemlerin dişlere bağlanma kuvvetinin; çiğneme kuvvetlerine, ark tellerinin uyguladığı kuvvetlere ve hastalarının kötü alışkanlıklarının oluşturduğu gerilimlere dayanabilecek miktarda olması gerekmektedir. ${ }^{6}$ Çok yüksek bağlanma kuvvelerinin tedavi bitiminde braketlerin söküm sırasında mine çatlaklarına ya da minede kırılmalara yol açabileceğinden dolayı istenmemektedir. ${ }^{7}$ Çalışmalar yeterli bağlanma kuvvetinin 8,10 megapascal (MPa) arasında olması gerektiğini belirtmektedir. ${ }^{6,8}$ Minenin kırılma gücü olan 14 MPa'dan daha az miktarda bağlanma kuvveti olması gerektiği belirtilmektedir. ${ }^{9}$

Sabit ortodontik tedaviler, maloklüzyonların tedavi edilmesi ve giderilmesi amacıyla yapılmaktadır. Tedavide braketler, ark telleri, elastik ligatürler, tel ligatürler plak retansiyonunu arttırıcı etkenler olabilmektedir. Bu durum oral hijyen girişimlerini zorlaştırmaktadır. ${ }^{10}$ Ortodontik tedavilerde, oral hijyenin sağlanması için hastalara tedaviye başlamadan önce oral hijyen motivasyon eğitimleri verilmektedir. ${ }^{11,12}$

Tüm ülkede ve dünyada olduğu gibi Sakarya Üniversitesi Diş Hekimliği Fakültesi Ortodonti Kliniğinde aktif ortodontik tedavisi devam etmekte olan hastaların COVID-19 pandemi dönemi içerisinde alınan tedbirler kapsamında rutin kontrollerinde aksama olmuştur. Olağanüstü yaşanan bu durum karşısında hastalarda motivasyon eksikliği ile birlikte yeme içme alışkanlıklarına dikkat etmeme ve oral hijyenlerine yeterli özeni göstermedikleri gözlemlenmiştir. Bu çalışmada amaç hastalarda COVID-19 pandemi dönemi içerisinde braketin dişten ayrılması ve oral hijyen durumlarını tespit etmektir.

\section{Yöntem}

Bu çalışma Sakarya Üniversitesi Diş hekimliği Fakültesi Ortodonti Kliniği'nde (11.06.2020-30.06.2020) COVID-19 pandemi süresinde aktif olarak ortodontik te- 
davisi devam eden 102 hasta üzerinde klinikte yapılan bir anket çalışmasıdır. Sakarya Üniversitesi Girişimsel Olmayan Klinik Araştırmalar Etik Kurulu 10.06.2020 tarihli 71522473/050.01.04/348 sayılı onayı ile yapılmıştır. Çalışma esnasında Helsinki Deklarasyonu ilkelerine uyularak gerekli hasta onamları alınmıştır. Çalışmaya katılım gönüllük esasına göre belirlenmiş olup, 102 anket formunun tamamı geri dönmüş olup, katılım oranı \%100'dür. Çalışmaya katılmayı kabul eden, aktif ortodontik tedavisi devam eden, zihinsel herhangi bir engeli olmayan hastalar dahil edildi. Tüm hastalara COVID-19 pandeminin başlangıç döneminden itibaren ortalama 2,5 ay sonra rutin kontrol seansları yapılırken tarafımızdan hazırlanan sosyodemografik anketle birlikte, diş yüzeyinden ayrılan braket sayılarının tespitini içeren bir soru ve aynı zamanda oral hijyen durumunu belirlemek için araştırmacı tarafından plak indeksi (PI) ${ }^{13}$ birlikte uygulandı. Çalışmada dental plak miktarı için bütün dişlerin meziyal, distal, bukkal, palatal yüzeyleri değerlendirildi. Plak indeksi (PI) ${ }^{13}$ sınıflandırması kullanılan değerlendirme 0 ; dişeti kenarında plak yok, 1: Serbest dişeti kenarında ve komşu bölgeye yapışmış film halinde plak varlığı, 2: Dişeti cebi ve gingival marjinde ve/veya komşu diş yüzeyinde çıplak gözle izlenebilen orta derecede yumuşak eklenti birikimi, 3: Dişeti cebi ve/veya gingival marjin ve komşu diş yüzeyinde bol miktarda yumuşak eklenti, şeklinde yapıldı.

\section{İstatistiksel Analiz}

Verilerin analizi SPSS Statistics 17.0 paket programında oral hijyen durumu için plak indeks değerlendirmesinde one-way ANOVA, bağımsız örneklemler için t testi, ve kırılan braket sayılarının cinsiyetlere göre karşılaştırılmasında Ki-kare testi kullanılmıştır. Araştırmadaki verilerin anlamlılık düzeyi $\mathrm{p}<0,05$ olarak belirlenmiştir.

\section{Bulgular}

Tablo 1'de görüldüğü gibi periodontal plak indeks değerlerinde erkeklerin kadınlarda anlamlı düzeyde daha yüksek olduğu tespit edildi $(\mathrm{p}=0,048)$ Tablo 2'de 13-22 yaş grubunda en yüksek ortalama değerlerde plak indeks
(PI) tespit edildi. Yaşa göre ortalama plak indeks değerleri karşılaştırıldığında ise en yüksek ortalama plak indeks (PI) değerinin 13-22 yaş grubunda olduğu, bunu sırasıyla 33-42 yaş ve 23-32 yaş grubunun takip ettiği tespit edildi. Ayrıca tüm gruplar arasında farklılığın anlamlı olduğu belirlendi $(\mathrm{p}=0,025)$ (Tablo 2).

\begin{tabular}{|c|c|c|c|c|}
\hline & & \multicolumn{3}{|c|}{ Plak İndeksi (PI) } \\
\hline & & MİN & Mean \pm SD & MAX \\
\hline \multirow{3}{*}{ Cinsiyet } & $\begin{array}{l}\text { Kadın } \\
(\mathrm{n}=54)\end{array}$ & 0,49 & $0,55 \pm 0,01$ & 0,61 \\
\hline & $\begin{array}{c}\text { Erkek } \\
(\mathrm{n}=48)\end{array}$ & 0,93 & $0,94 \pm 0,01$ & 0,95 \\
\hline & $\begin{array}{l}\text { Student's } \\
\text { t-testi }\end{array}$ & \multicolumn{3}{|c|}{$p=0,048$} \\
\hline
\end{tabular}

\begin{tabular}{|c|c|c|c|c|}
\hline & & \multicolumn{3}{|c|}{ Plak İndeksi (PI) } \\
\hline & & MİN & Mean \pm SD & MAX \\
\hline \multirow{4}{*}{ Cinsiyet } & $\begin{array}{c}13-22 \text { yaş } \\
(\mathrm{n}=42)\end{array}$ & 0,59 & $0,65 \pm 0,01$ & 0,71 \\
\hline & $\begin{array}{c}\text { 23-32 yaş } \\
(\mathrm{n}=36)\end{array}$ & 0,33 & $0,37 \pm 0,02$ & 0,41 \\
\hline & $\begin{array}{c}33-42 \text { yaş } \\
(\mathrm{n}=24)\end{array}$ & 0,51 & $0,52 \pm 0,01$ & 0,53 \\
\hline & ANOVA & \multicolumn{3}{|c|}{$\mathrm{p}=0,025$} \\
\hline
\end{tabular}

Tablo 3'te diş yüzeyinden ayrılan braket sayılarının cinsiyetlerin kendi içerisinde kıyaslaması yapılmıştır. Bütün braketleri diş yüzeyinde bağlantısı mevcut olan kadın sayısı toplam kadın sayısında en fazla oranı oluşturmaktadır $(n=20, \% 19,9) .2$ ve üzeri sayıda braketi diş yüzeyinden ayrılan kadın oranı $(n=10, \% 0,09)$ olarak en düşük tespit edildi. Erkeklerde en fazla 1 braketi diş yüzeyinden ayr1lan hastalar $(\mathrm{n}=16, \% 15,6)$ oranında görüldü. 1 braketi diş yüzeyinden ayrılan hasta sayı oranı $(n=16, \% 15,6)$ braketi diş yüzeyinden ayrılmayan erkek sayılarına $(n=13, \% 12,7)$ oranla daha yüksek olduğu görüldü. Kadınların kendi içe- 
risinde $(\mathrm{p}=0,028)$ ve erkeklerin kendi $(\mathrm{p}=0,037)$ içerisinde braketin diş yüzeyinden ayrılması ve ayrılmaması oranlarında anlamlı farklılıklar olduğu tespit edildi.

\begin{tabular}{|c|c|c|c|c|c|c|}
\hline \multicolumn{7}{|c|}{$\begin{array}{l}\text { Tablo 3. Diş yüzeyinden ayrılan braket sayılarının cinsiyet } \\
\text { durumuna göre kıyaslama }\end{array}$} \\
\hline & & \multicolumn{4}{|c|}{ Diş yüzeyinden ayrılan braket sayısı } & \\
\hline & & 0 & 1 & 2 & 2 ve üzeri & \multirow{2}{*}{$\mathrm{p}$} \\
\hline & & $\mathrm{n}(\%)$ & $\mathrm{n}(\%)$ & $\mathrm{n}(\%)$ & n (\%) & \\
\hline \multirow{2}{*}{ 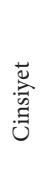 } & 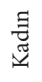 & $20(\% 19,6)$ & $12(\% 11,7)$ & $12(\% 11,7)$ & $10(\% 0,9)$ & 0,028 \\
\hline & 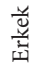 & $13(\% 12,7)$ & $16(\% 15,6)$ & $13(\% 12,7)$ & $6(\% 0,05)$ & 0,037 \\
\hline $\mathrm{Ki}-$ & & $\mathrm{p}<0,05$ & & & & \\
\hline
\end{tabular}

\section{Tartışma}

Beklenmedik bir anda aniden ortaya çıkan ve bütün dünyayı hızlıca etkisi altına alan ve halen etkisi devam eden COVID-19 pandemi ister istemez bütün bireylerde yaşam rutinlerinde değişimlere neden olmuştur. Ortodonti kliniğimizde aktif ortodontik tedavisi devam eden hastalarda pandemi süresinde rutin ortodonti tedavi kontrollerine ara verilmek durumunda kalınmıştır. Bu çalışmada COVID-19 pandemi dönemi başlangıcında 18.03.202001.06.2020 tarihleri arasında randevularına düzenli gelememelerinden dolayı meydana gelen oral hijyen eksikliğini ve diş yüzeyinde ayrılan braket sayılarının yaş ve cinsiyetlere göre değerlendirme amaçlanmıştır.

Sabit ortodontik tedavilerde mikrobiyal dental plak birikimini inceleyen pek çok çalışma mevcuttur. ${ }^{14-16}$

Çalışmada bütün hastalara ortodontik tedaviye başlamadan önce oral hijyeni sağlamak için oral hijyen motivasyon bilgilendirmesi yapılmıştır. Rutin kontrolleri sırasında eksik bulunan noktalar tekrarlanarak hastalar sürekli bilgilendirilmiştir. Ancak hazırlıksız yakalanılan COVID-19 pandemi döneminde hastalarda kontrollerdeki aksamalardan ötürü oral hijyendeki eksiklik beklenilen bir durum olacağ rinde mikrobiyal dental plak varlığı gözlemlenmiştir. Ortodontik tedavi başlangıcından sonra yapılan kontrollerde diş yüzeylerinde bulunan braketler, ark telleri, bantlar nedeniyle plak birikiminin arttı̆̆ını belirten çalışmalar mevcuttur. ${ }^{15,17}$

COVID-19 pandemi döneminde ortalama olarak 2,5 ay hastaların kontrollerinde aksama görülmüştür. Bu süreç sonrasındaki ilk kontrole geldiklerinde bütün hastalarımizda her yaş gurubunda mikrobiyal dental plaklarda artış tespit edilmiştir. Bu çalışmada en yüksek plak indeks değerlerinin 13-22 yaş gurubunda olduğu gözlemlenmiştir. 18-32 yaş grupları arasında sabit ortodontik tedavi başladıktan sonra bütün bireylerde plak birikimin artmış olduğu bir başka araştırıcı tarafından daha önce de belirtilmektedir. ${ }^{14}$ Oral hijyen problemleri pek çok hastada sabit ortodontik tedavi başlangıcından ortalama olarak 1 ay sonra görülebildiği belirtilmektedir. Uzun dönem sonunda çapraşık dişler düzelmeye başlayıp, diş fırçalamanın daha etkin bir şekilde gerçekleşmesi ile gingival sağlığın iyiye gittiği belirten araştırıcılar da bulunmaktadır.18 Sabit ortodontik tedavide plak indeks değerlerinin tedavi başladıktan 48 saat sonra maksimum düzeye ulaştığını, 1 ay sonrasındaki kontrollerde tedavi öncesideki değerlere göre daha yüksek değerlerde olduğu belirtilmektedir. ${ }^{19}$ Naranjo ve ark., plak indeks değerlerinin kadın hastalarda 3 aylık dönem içerisinde tedavi etmedikleri kontrol grubundaki kadın hastalarla kıyaslaması sonucunda istatistiksel olarak anlamlı olarak plak indeks değerlerinde artış gösterdiğini belirtmektedir. ${ }^{20}$

Bu çalışmada erkek hastaların kadın hastalara göre plak indeks değerlerinde anlamlı derecede daha yüksek olduğu tespit edildi. Bulgumuz daha önce yapılmış olan çalışmalarda erkeklerin kadınlardan daha fazla plak birikimi gözlendiği belirten bulgular ile benzerdir. ${ }^{16,21}$ Bunun yanında erkekler ve kadınlar arasında plak birikimi açısından farklılık olmadığını belirten çalışma da mevcuttur. ${ }^{14}$ Kadınlar ve erkekler arasında plak birikim farklılığını erkeklerdeki tükürük bezinin daha büyük olmasına aynı za- 
manda erkekler ve kadınlardaki hormonal değişime bağlı olarak tükürük salım hızındaki farklılıktan kaynaklandığı belirtilmektedir. ${ }^{22}$ Tedavi planlaması farklılığının da plak birikimlerinde farklılık oluşturabileceği belirtilmektedir. ${ }^{23}$

Çalışmada aktif ortodontik tedavi gören kadınların sayısı 54’tür. Kadın hastalarımız erkek hastalarımıza göre daha fazla sayıda braketin diş yüzeyinden ayrıldığı tespit edilmiştir. Bu oranın yüksek olmasının nedeninin COVID-19 pandemi döneminde hastalarımızın stres altında hissetmelerinden ötürü yeterli özeni göstermemelerinden kaynaklandığı düşünülmektedir. Sabit ortodontik tedavide braketlerin bağlanması için minenin kırılma gücü olan 14 MPadan daha az miktarda bağlanma kuvveti olması gerektiği belirtilmektedir. ${ }^{9}$ Yapılan in-vitro çalışmalarda braketlerin diş yüzeyinde tutunması için adeziv sistemleri ve yöntemleri ile bağlanma dayanımları incelenmektedir. ${ }^{24-26}$ Ağız içi koşulları, sıcaklı̆̆ı, nemi, pH, farklı yönlerden ve kontrolsüz gelen çiğneme basınçları, hastanın oral hijyeni, dental plak varlığı tam anlamıyla in-vitro ortamlara yansıtılamamaktadır. Bundan ötürü in-vitro testlerin sonuçları arasında farklılık görülebilmektedir. ${ }^{24,26}$

Düzenli kontrollerinizi sağlayamadığımız bu dönem içerisinde hastaları braketlerini korumaları yönünde gerekli telkin ve motivasyonları yeterince verememeden ötürü bireylerde diş yüzeyinden braket ayrılma oranının yüksek olduğunu düşünülmektedir. Diş yüzeyinden ayrılan braketi olan hasta sayısı diş yüzeyinden braketi hiç ayrılmayan hasta sayısına göre anlamlı derecede yüksek olduğu tespit edildi. Elekdağ ve ark., 37 hasta için klinik performans değerlendirmesinde iki farklı bonding prosedüründe başarısızlık oranlarını \%0,6 olarak tespit etmiş ve gruplar arasında istatistiksel olarak anlamlılık olmadığını belirtmektedir. ${ }^{27}$ Murfitt ve ark., hastalarda klinik performans değerlendirmesinde farklı iki bonding yöntemi ile braket yapıştırılmasını gerçekleştirmiştir. Self-etch yöntemin, konvansiyonel yönteme göre bağlanma başarısızlığı gösterdiğini belirtmektedir. ${ }^{28}$
Bütün hastalarımıza sabit ortodontik tedavi başlangıcında bütün dişlerine eksiksiz braketlerin hepsi yerleştirilmiştir. Hastalar her seans kliniğe kontrole geldiklerinde araştırıc1 tarafından tedavileri gerçekleştirilip yine bütün dişlerde braket kontrolü sağlanıp dișten ayrılan braketin var olması durumunda tekrar yerleştirilmiştir. Bu bakımdan pandemi dönemi başlangıcında bütün bireylerde tüm dişlerinde braket mevcuttur. Ancak çalışmada tedavi başlangıcından önce plak indeks kayıtlarının alınmamış olması bu çalışmanın limitasyonu oluşturmaktadır. Rutin olarak ortodonti kliniğinde sabit ortodontik tedaviye başlamadan önce muhakkak birincil olarak gerekli olan bütün periodontal tedavilerin hepsi yapılıp, yeterli düzeyde oral hiyjen motivasyon eğitimi verilip, konrolleri sağlandıktan sonra ancak sabit ortodontik tedavilere başlanmaktadır. Bundan ötürü hastalarda başlangıç aşamasında plak indeks değerlerinin çok düşük olduğu hatta hiç dental mikrobiyal plak olmadığ 1 düşünülebilinir. Gelecekteki çalışmalarda periodontal sağlığı belirlemek adına kullanılan parametrelerde plak indeksi ile birlikte, gingival indeks, sondalamada kanama yüzdesi, periodontal cep derinliğine birlikte bakılması daha kapsamlı sonuçlar vereceği düşünülmektedir.

\section{Sonuç}

Çalışmamın sonucunda COVID-19 pandemi başlang1cında rutin kontrollerinin yapılamamasından ötürü erkek hastaların oral hijyeni sağlamada kadınlara kıyasla daha yetersiz oldukları gözlemlenirken, diş yüzeyinden ayrılan braket sayıları oranlarının erkeklerin kadınlardan daha düşük oranda olduğu görülmektedir. 
J Biotechnol and Strategic Health Res. 2020;4(3):266-271

TOPAL, Ortodonti Hastalarında Covid-19 Pandemisi

\section{Kaynaklar}

1. Lu R, Zhao X, Li J, et al. Genomic characterisation and epidemiology of 2019 novel coronavirus: implications for virus origins and receptor binding. Lancet. 2020; 395 (10224):565-74.

2. T.C. Sağllk Bakanlı̆̆ 2020. Türkiye Günlük Koronavirüs Tablosu. https://covid19.saglik. gov.tr/.(27.05.2020)

3. Xiao C. A novel approach of consultation on 2019 novel coronavirus (COVID-19)Related psychological and mental problems: structured letter therapy. Psychiatry Investig. 2020 ; 17(2): 175-6.

4. Yımaz D. Diş hekimliği ve dental klinikler yönünden COVID-19 enfeksiyonu. J of Biotec Strate Health R. 2020; 1(Özel sayt):22-8.

5. Atik E, Ciğer S. Ortodontik bonding ișleminde self-etch primer ve konvansiyonel asit-etch tekniklerinin karşslaştırilması. Atatürk Üniv. Diş Hek Fak Derg. 2014; 24(3): 452-7.

6. Lopez JI. Retentive shear strengths of various bonding attachment bases. Am J Orthod 1980; 77(6):669-78.

7. Millett DT, Glenny AM, Mattick RCR, et al. Adhesives for fixed orthodontic bands. Cochrane Database of Systematic Reviews. 2007; doi:10.1002/14651858.CD004485.pub3.

8. Keizer CJ, Arends J. Direct bonding of orthodontic brackets. Am J Orthod 1976; 69(3):31827.

9. Retief DH. Failure at the dental adhesive-etched enamel interface. J Oral Rehabil 1974; 1(3):265-84

10. Ousehal L, Lazrak L, Es-Said R, et al. Evaluation of dental plaque control in patients wearing fixed orthodontic appliances: a clinical study. Int Orthod 2011; 9(1): 140-55.

11. Lees A, Rock WP. A comparison between written, verbal, and videotape oral hygiene instruction for patients with fixed appliances. J Orthod 2000; 27(4): 323-8.

12. Yetkin AZ, Esenlik E, Çă̆lar F. Farklı oral hijyen motivasyon yöntemlerinin sabit ortodontik tedavi gören bireylerin halitozis düzeylerine etkisi. Atatürk Üniv Di Hek Fak Derg. 2013; 21(3): 307-12.

13. Silness J, Löe H. Periodontal disease in pregnancy II. Correlation between oral hygiene andperiodontal condition. Acta Odontol Scand 1964; 22(1): 121-35.

14. Rakhsan H, Rakhshan V. Effects of the initial stage of active fixed orthodontic treatment and sex on dental plaque accumulation: A preliminary prospective cohort study. Saudi I Dental Research.2015; 6(2):86-90.

15. Ristic M, Vlahovic Svabic M, Sasic M,et al. Clinical and microbiological effects of fixed orthodontic appliances on periodontal tissues in adolescents. Orthod Craniofac Res 2007; 10(4):187-95.
16. Lara-Carrillo E, Montiel-Bastida NM, Sanchez-Perez L, et al. Effect of orthodontic treatment on saliva, plaque and the levels of Streptococcus mutans and Lactobacillus. Med Oral Patol Oral Cir Bucal 2010;15(6): e924-9.

17. Zachrisson S, Zachrisson BU. Gingival condition associated with orthodontic treatment. Angle Orthod 1972; 42(1):26-34.

18. Glans $R$, Larsson E, Øgaard B. Longitudinal changes in gingival condition in crowded and noncrowded dentitions subjected to fixed orthodontic treatment. Am J Orthod DentofacialOrthop 2003; 124(6): 679-82.

19. Sinclair P. Cannito F. Goates J. Solomos F. Alexander M. Patient Responses To Lingual Appliances. J Clinic Orthod 1986; 20 (6): 396-04.

20. Naranjo AA, Trivino ML, Jaramillo A, et al. Changes in the Subgingival Microbiota And Periodontal Parameters Before And 3 Months After Bracket Placement. Am J Dentofacial Orthop 2006; 130 (3): 275.e(17-22)

21. Edith LC, Montiel-Bastida NM, Leonor SP, et al. Changes in the oral environment during four stages of orthodontic treatment. Korean J Orthod 2008; 40(2): 95-05.

22. Bollen AM, Cunha-Cruz J, Bakko DW, et al. The effects of orthodontic therapy on periodontal health: a systematic review of controlled evidence. J Am Dent Assoc 2008; 139(4):413-22.

23. Scheurer PA, Firestone AR, Bürgin WB. Perception of pain as a result of orthodontic treatment with fixed appliances. Eur J Orthod 1996; 18(1):349-57.

24. Mirzakouchaki B, Kimyai S, Hydari M, et al. Effect of self-etching primer/ adhesive and conventional bonding on the shear bond strength in metallic and ceramic brackets. Med Oral Patol Oral Cir Bucal 2012;17(1) :e164-70.

25. Habibi M, Nik TH, Hooshmand T. Comparison of debonding characteristics of metal and ceramic orthodontic brackets to enamel: an in-vitro study. Am J Orthod Dentofacial Orthop 2007;132(5):675-9.

26. Theodorakopoulou LP, Sadowsky PL, Jacobson A, et al. Evaluation of the debonding characteristics of 2 ceramic brackets: an in vitro study. Am J Orthod Dentofacial Orthop 2004; 125(3):329-36.

27. Elekdag-Turk S, Isci D, Turk T, et al. Sixmonth bracket failure rate evaluation of a selfetching primer. Eur J Orthod 2008; 30(2):211-6.

28. Murfitt PG, Quick AN, Swain MV, et al. A randomised clinical trial to investigate bond failure rates using a self-etching primer. Eur J Orthod 2006; 28(5):444-9. 